\title{
SEMANTIKA IMENICE BIĆE U PROZNIM DJELIMA ŽELJKE ČORAK
}

Prilog se bavi semantičkim sadržajem navedene imenice u prozi poznate ličnosti suvremene hrvatske kulture, $i$ to u četiri temeljne kategorije (ljudi, životinje, stvari, apstraktni pojmovi), s metaforama, personifikacijama i uvijek prisutnom afektivnošću.

1. O bogatstvu stila i jezika opusa Željke Čorak do sada je dovoljno rečeno ${ }^{1}$, a semantička je komponenta u tome naravno jedna od glavnih. Tom je dijelu lingvistike posve-ćen i ovaj prilog, koji analizira semantički sadržaj imenice biće. I ovdje kao i u pret-hodnim radovima, proučavamo samo autoričinu prozu. Budući da je semantika usko povezana sa sadržajem tekstova, prije primjerâ dajemo kratak prikaz korpusa krono-loškim redom. Sva su djela izašla u Zagrebu.

1) Kaleidoskop, 1970: zbirka kritika i osvrtâ na izložbe i druge manifestacije, kao i neka urbanistička pitanja: mladenačko a već zrelo djelo, odlično informirano, s kritičkim sudovima i duhovitim poentiranjima. Kratica KAL.

2) Lanjski snijezi, 1979: zbirka prepjevâ francuske lirike (od Guilhema IX, vojvode akvitanskoga, do baroka) i francuskih pjesama R. M. Rilkea, is time povezanih autoričinih eseja, također sa bogatim refleksijama i kritičkim zapažanjima. Kratica LS.

3) U funkciji znaka. Drago Ibler i hrvatska arhitektura između dva rata, 2000 (1. izd. 1981), doktorska disertacija (obranjena g. 1976), interpretacija arhitekture kao svojevrsnoga lingvističkog sustava u semiotičkom ključu, sa širokim pogledima na kulturnu i opću povijest. Kratica UFZ.

4) Zagrebačka katedrala, 1988 (u suautorstvu s Anom Deanović i za fotografije Nenadom Gattinom): monografija u kojoj Željka Čorak obrađuje XIX. stoljeće, posebno obnovu katedrale nakon potresa g. 1880, pisana vrlo angažirano i toplo, s pozitivnim sudom o Hermannu Bolléu. Kratica ZK.

5) Krhotine. Prilog poznavanju hrvatske provincije u devetnaestom stoljeću, 1991: najpoznatije i najljepše djelo naše autorice; u osnovi memoari, ali i znanstvenostručni prikaz kuća, osoba, inventara i svega s time povezanoga, a što je u golemom dijelu uništeno u požaru u Prezidu g. 1942. i kasnije, u reformama i konfiskacijama, od 1945. dalje. Krhotine su apsolutno jedinstveno djelo, kako se točno reklo, brez prethodnih uzora i suvremenih paralela ${ }^{2}$, pisano s erudicijom, filozofskim refleksijama,

1 V. Bošković 1997, Maroević 1994, Šafranek 1998, Škunca 1995, Tekavčić 1997, 1998 a-d, 1999.

2 »Kažemo li da je riječ o knjizi koja u našoj literaturi ne poznaje prethodnike i stilske srodnike, dovoljno smo kazali u prilog njezine iznimnosti i nepotkupljive vrijednosti« (Bošković 1997, str. 59). 
aluzijama, ali i s vrlo jasnom nostalgijom i nevjerojatnom senzibilnošću, a sve to bez ikakvoga revanšizma, dostojanstveno, uzvišeno i pomalo indirektno. Taj naslov, naveden kao jedini u Hrvatskom općem leksikonu (HOL, v. bi-bliografiju) ${ }^{3}$, bez sumnje će ostati kao autorićin monumentum aere perennius. Kratica KR.

6) Oproštajno pismo gospodinu Mitterrandu, 1993: nevelika zbirka osam tekstova (od kojih je četvrti eponim cijeloj knjizi) na temu nedavnog rata u Hrvatskoj i Bosni i Hercegovini, prožetih oštrom kritikom agresora s jedne, i farizejštine $\mathrm{i}$ indolentnosti Zapada s druge strane. Svi su prilozi puni ogorčenosti, ironije i sarkazma, ali i ponosa na povijesnu i kulturnu vrijednost vlastitoga naroda. Tom se knjigom Željka Čorak afirmirala i na polju politike, naročito kulturne politike, a mračni i ogorčeni ton svih tekstova ima veze s našom temom, kako ćemo kasnije pokazati. Kratica OPGM.

7) Zagreb, pisani prostor, 1994: zbirka tekstova (objavljenih od 1966. do 1987.g.) o arhitektonskim i urbanističkim problemima Zagreba i povijesti nekih poznatih objekata (Muzej Mimara, Obrtna škola i Muzej za umjetnost i obrt, katedrala, krematorij, zahvati u Jelačićev trg i drugo), sve s potpunim poznavanjem problematike, uobičajenim angažmanom i duhovitim kritičkim stilom. Kratica ZPP.

8) Predgovor (str. 5) u knjizi Željka Zorice Fantastični bestijarij ili usnuli čzvari grada Zagreba (Zagreb 1996): s mnogo mašte i topline napisan uvod u knjigu koja se bavi opisom zagrebačkih spomenika i njihovim fantastičnim, irealnim tumačenjima. Kratica $\breve{Z Z}$.

9) Ptica mojega jezika, "Vijenac" 13.11.1997: napis o više aktualnih problema; unatoč tome, tekst pun poetičnosti i osjećajnosti, ovaj put s jasnom osudom svega tragičnoga u obitelji, a naročito žalosne sudbine autoričine majke. Po sadržaju i stilu dostojan nastavak Krhotina (koji ne bez razloga nosi nadnaslov Nove Krhotine!). Kratica PMJ.

2. U pregledanom korpusu našli smo 48 primjera s imenicom biće. Dimenzije ovoga priloga nalažu dakako selekciju, pa donosimo taj izbor, redom kao u prethodnom paragrafu, s kraticom i stranicom. Primjeri su kontekstualizirani i, koliko je potrebno za razumijevanje, protumačeni.

1) [O slikarstvu Gabrijela Stupice] Još uvijek zatim preostaje svijet stvari [...] Savez bića $i$ stvari: mala djevojcica sjedi na stolici i jedino su njih dvije u cijelom svijetu koji ih okružuje [...] (KAL 34)

2) [isti kontekst] Savez bića i bića: uho slikara koje sluša nečujan mali glas, ruka u gotovo beznadnoj dubini ipak na domaku drugog bica. (KAL 34-35)

3) [Osvit na slikarstvo Nives Kavurić-Kurtović] Ljudsko biće u odnosu prema drugim ljudskim bićima; ljudsko biće u odnosu prema nespoznatljivoj biti stvari;

3 U vezi sa Željkom Čorak u tom se leksikonu opaža izvjesna nedosljednost. U tekstu natuknice kaže se, naime, da je ona hrvatska povjesničarka umjetnosti, da se bavi hrvatskom arhitekturom od historicističke do suvremene, osobito zagrebačkom katedralom, dok se njezina književna djelatnost spominje samo riječju književni$c a$; od tekstova se, pak, navode samo Krhotine kao "glavno književno djelo«. Ako je kao glavni naslov navedeno $\mathrm{knj}$ iž ž v o djelo, onda je u natuknici trebalo reći da je Željka Čorak i kritičarka, esejistica, prevoditeljica i (g. 1996) potpredsjednica hrvatskoga PEN-a; ako pak praktički cijela natuknica govori o njezinu umjetničkom i arhitektonskom radu, valjalo je navesti glavne naslove i iz toga područja: barem UFZ, ZK, ZPP. 
ljudsko biće pred naletom svoje neznane unutrašnjosti; ljudsko biće koje želi progledati kroz naplavine svakodnevnog. (KAL 41)

4) [O čuvanju ali i gubitku kulturne baštine] ako se odričemo mjesta koja su nas zadužila, znak je da umire nešto u nama: lišavajući se svoje povijesti, to jest svog zavičaja, biće se nepopravljivo lišava sebe sama. (KAL 78)

5) Tema: Gaston Bachelard i svjetiljka] Rasvjetljujući svjetiljku i ljudsko biće u njezinu krugu, stari filozof otvorio je jedan »nadzirani prostor«u kojemu će zadugo svaka svjetiljci upućena misao biti i sjećanje na njega. (KAL 135)

6) [O Rilkeovim pjesmama, koje se često bave stvarima] One su čitanje stvari kao znakova i kao pisma, pa su i same gotovo simboličan izlazak iz vlastitog jezika ususret govoru drugih bica. (LS 114)

7) [Isti kontekst] Rilke je secesijski pjesnik [...] upravo po središnjem mjestu koje posrednička bića stvari imaju u njegovu pjesništvu. (LS 121)

8) [O zgradi Epidemiološkog zavoda u Zagrebu] To se zdanje ne trudi biti strojem nego naprotiv bićem. (UFZ 45)

9) [Razmatranje o zagrebačkoj katedrali] Katedrala je biće kojemu je jedna od osnovnih zadaća da nas sve nadživljuje. (ZK 295)

10) [Slučajni susret s ostatkom jednog prezidanskog spomenika] neobično slijepljeno biće koje je privuklo moju pažnju. Bio je to anđeo s Vjeričina ili Hinkova groba. (KR 85)

11) [O obiteljskom foto-albumu, s aluzijom na $\mathrm{H}$. Boscoa, koji voli biljke jer umiru tamo gdje su rodile] Nanin modri album s metalnim okovima bio je moj herbarij za bića. (KR 104)

12) [O lijepoj djedovoj sestri Toti] Tota je bila, što bi se danas reklo, sofisticirano, estetizirano biće. [...] Tota je bila stilsko biće. (KR 116-117)

13) [O dva starinska obiteljska džepna sata] Razlika je možda u milimetru. Ali hoće reći da je svako biće biće za sebe. (KR 126)

14) [O garnituri čašica, $\mathrm{s}$ aluzijom na uništenje inventara] Preživjelo je samo šest ovih malih, bojom obilježenih bića. (KR 129)

15) [Poglavlje o Totinom ogledalu, puno refleksija i gotovo okultnih elemenata.] Zna se koliko su ogledala opasna bića. (KR 134)

16) [O preostaloj Totinoj garderobi] Ovi komadi čipaka, ostaci njezinih haljina [...] dovoljni su za rekonstrukciju bića. (KR 139)

17) [Kratki opis jedne štale, koju je autorica rado posjećivala] Jer su se u štali obićno nalazili telčići, zečići i druga sitna dlakava i strigava bića. (KR 178)

18) [Autoričina majka je bila zamoljena da za autoričinu kćerku, dakle svoju unuku, sačuva »les très riches heures ${ }^{4}$ iz Prezida] godišnja doba s mirisima i okusima, sjećanje na betlehemska bića, bezazlene sjene kravica, konja i pasa... (KR 180)

4 To je dio naslova najpoznatijega brevijara izraženoga za vojvodu i velikoga bibliofila Jeana de Berryja (13401416; v. HOL). Podatak zahvaljujemo sveučilišnoj lektorici prof. Blaženki Bubanj. 
19) [Autorica je u mladosti voljela čitati u prezidanskom vrtu, a] Kao pojačanje, neko je dežurno krpeno biće ležalo kraj mene [...] (KR 192) [bila je to dakako lutka na stalku starog glačala kao »krevetiću«]

20) [Autorica se s ganućem sjeća krasnih naušnica svoje majke] Svrha tih naušnica na svijetu [...] bila je da mi pokažu neizmjerljivu veličinu bliskog bića. (KR 203)

21) [U vezi s rušenjem starih kuća na početku Tkalčićeve] Gradove, kao i bića, volimo jer se razlikuju. (ZPP 35)

22) [U vezi sa vlastitim proučavanjem zagrebačke katedrale] željela sam [...] vidjeti jasno razloge i dosege svojih sklonosti. Na vagi su dakle bila dva bića istodobno: biće katedrale i moje [...] (ZPP 161)

23) [Hermann Bollé i zagrebačka katedrala] Hermann Bollé nije zbrisao niti idealizirao prošlost na licu »svoje» katedrale. [...] Zagrebačka katedrala ostala je osobna, biće prepoznatljivog, očuvanog identiteta. (ZPP 166)

24) [Simbolika ukrasa na zagrebačkim zgradama i sl.] Kako ne zavidjeti na pretvaranju bića u biće-uspomenu koje je trajnije $i[. .$.$] »fizičnije» od tjelesnog stvora [. .].(Z ̌ Z)$

25) [Odlomak o obiteljskim problemima i teškoj bolesti autoričine majke] Mila Totka [...] suautorica Krhotina, našla se iz čovjeka pretvorena u nepomično biće, bez riječi, bez raspolaganja sobom. (PMJ)

\section{Semantička analiza}

3.1 Iz primjerâ se vidi da imenica biće dolazi u četiri semantičke kategorije, koje se prema komponencijalnoj analizi mogu formulirati kao tri binarne alternative, s tim da se druga i treća primjenjuju na pozitivni odgovor na prvu odnosnu drugu:

1) [konkretno/apstraktno]

2) [živo/neživo]

3) [čovjek/životinje]

Te četiri kategorije mogu se dakle formulirati kao 1) [čovjek], 2) [životinje], 3) [stvari], 4) [apstrakti].

Po kognitivnom gledanju unutar svake od kategorija moguće su distinkcije skalarnog tipa: Tota (12) je sigurno više prototipična u prvoj kategoriji nego nepomično biće (25), telčići i zečići (17) bolji su prototip u drugoj kategoriji nego betlehemske kravice itd. (18), kao što su čašice (14) prototipičnije u trećoj kategoriji nego gradovi (21) ili katedrala $(9,23)$ itd. U to međutim ovdje ne možemo dublje ulaziti.

3.2. Naše se binarne semantičke alternative mogu prikazati obliku »stabla« $\mathbf{i}$ kao binarne formule s odgovorima $+/$ - (brojevi se odnose na primjere, od kojih je $22 \mathrm{dva}$ puta brojen, jer sadrži biće u kategorijama 1 i 3):

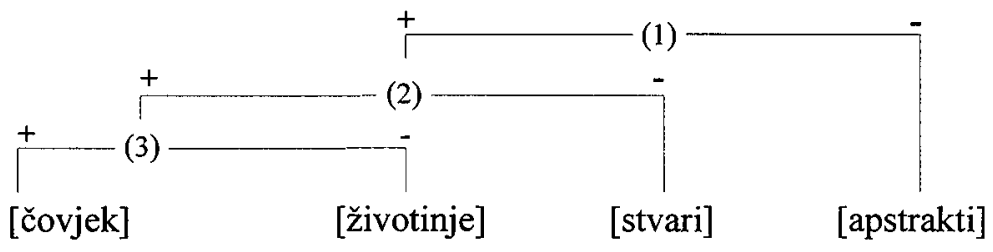


1) $[1+2+3+]=[$ čovjek]: $1,2,3,5,11,12,16,22,25$;

2) $[1+2+3-]=[$ životinje]: 17,18 ;

3) $\quad[1+2-]=[$ stvari $]: 6,7,8,9,10,14,15,19,20,22,23$;

4) $[1-]=[$ apstrakti $]: 4,13,21,24$

3.3. Značenje može biti izrečeno eksplicitno ili se može razabrati iz konteksta: usp. npr. za kategoriju [čovjek] primjere 1 i 12.

3.4. Od značenjâ koja nalazimo u suvremenim rječnicima hrvatskog jezika (Benešić 1985 i.d.: »stvorenje, narav, postojanje«; Anić 1998: »ono što živi, stvorenje; unutrašnja priroda čovjeka; život, postojanje; bit, suština«) u našim primjerima ostvaruju se gotovo isključivo prva značenja, a samo u nekim druga, npr. u sintagmi biće grada, ZPP str. 59. i 62.

3.5. Sve kategorije osim [čovjek] sadrže dakako personifikaciju, a o bogatoj metaforici ne treba ni govoriti.

3.6. U svim se primjerima osjeća autoričina simpatija, osjećajnost, toplina i srodne konotacije. To je naročito jasno u autoričinu obraćanju katedrali u 2. licu, kao živoj osobi (ZK: Ante scriptum i Post scriptum), a i u primjeru 25, koji striktno logički ne bi mogao uči u kategoriju [čovjek] (opozicija čovjek/nepomično biće), ali afektivna konotacija to ne samo dopušta nego upravo nalaže.

3.7. Na kraju, valja istaknuti još nešto. Svi primjeri imenice biće u istraženom su korpusu konotirani kao subjektivno pozitivni, tj. svi izriču, u vrlo različitoj mjeri - što će reći da i tu nalazi primjenu kognitivni pristup i skalarne pod-distinkcije - autoričinu simpatiju, sklonost, prijateljski stav (pa naravno i ljubav). To vrijedi i za primjer 15 , jer ni tu subjektivni stav nije negativan, nego uslijed spomenute »okultne« komponente možda samo malo simpatično »naježen«. Samo u jednom od pregledanih djela nema n i j e d n o g a primjera imenice biće, a to je OPGM. Kako smo rekli u uvodu, cijela je ta knjiga prožeta ironijom, sarkazmom, ogorčenošću i prkosom, pa se riječ biće sa svojom temeljnom pozitivnom subjektivnom konotacijom u tu atmosferu nikako ne uklapa (a onih nekoliko vedrijih pasusa u OPGM nije dovoljno da tu atmosferu razbije). I taj je detalj dokaz istančanosti sadržaja i njemu primjerenog jezika.

4. Semantička raznolikost i dodatne afektivne konotacije odraz su bogata duševnog i duhovnog života Željke Čorak, a jednako tako i bogatstva stila i jezika. Uvjereni smo da njezina djela pružaju neiscrpivo gradivo i za druge slične studije i da će se stručnjaci za to pozvaniji od potpisanoga autora latiti toga zlatnog rudnika suvremene hrvatske pisane riječi. 


\section{Navedena djela}

Anić 1998: V. Anić, Rječnik hrvatskoga jezika, Zagreb.

Benešić 1985 i d.: J. Benešić, Rječnik hrvatskoga književnog jezika od Preporoda do Ivana Gorana Kovačića, Zagreb.

Bošković 1997: I. J. Bošković, Prozna vremena, osobni abecedarij, Zagreb.

HOL: Hrvatski opći leksikon, ur. A. Kovačec, Zagreb 1996.

Maroević 1994: T. Maroević, What a Kaleidoscope - Željka Črak Krhotine (»Fragments«), The Bridge 3, str. $74-75$.

Šafranek 1998: I. Šafranek, lichen de ruines (A propos du livre de Željka Čorak Débris), Most - Le pont 3-4, str. 222-227.

Škunca 1995: A Tender Book of Hard Resistance: Željka Čorak interviewed by Andriana Škunca, The Bridge 9-10, str. $131-132$.

Tekavčić 1997: P. Tekavčić, O nekim problemima u jeziku suvremenih hrvatskih nefikcionalnih pisaca (na tekstovima Željke Črak), Filologija 28, str. 35-45.

Tekavčić 1998a: P. Tekavčić, Italianismi nella prosa non narrativa croata contemporanea (sulle opere di Željka Corak), Linguistica 38/2, str. 149-155.

Tekavčić 1998b: P. Tekavčić, Tvorba riječi u jednom zanimljivom korpusu, ib., str. 157-166.

Tekavčić 1998c: P. Tekavčić, Plurilinguismo nelle opere di una eminente personalità della cultura croata contemporanea (Željka Čorak), Incontri linguistici 21, str. 173-180.

Tekavčić 1998d: P. Tekavčić, O jednoj posebnoj vrsti zavisnih rečenica, na jednom zanimljivom korpusu, Suvremena lingvistika 45-46, str. 65-70.

Tekavčić 1999: P. Tekavčić, Latinizmi u djelima Željke Čorak, Rasprave Instituta za hrvatski jezik i jezikoslovlje 25, str. 345-357.

Ključne riječi: Hrvatsko biče, semantika, metafora, personifikacija, afektivnost.

Parole chiave: Croato biće, semantica, metafora, personificazione, affettività.

Key words: Croatian bice, semantics, metaphor, personification, affectivity.

\section{Povzetek}

\section{SEMANTIKA SAMOSTALNIKA BIĆE V PROZI ŽELJKE ČORAK}

Prispevek obravnava pomene hrvaške besede biće 'bitje' $\mathrm{v}$ proznih besedilih znane sodobne hrvaške umetnostne zgodovinarke in pisateljice. Beseda 'bitje' je konotirana vedno pozitivno in sicer $v$ štirih osnovnih semantičnih kategorijah: osebe, živali, materialni svet, abstraktni pojmi, ima pa tudi različne figurativne pomene, $v$ metaforah, personifikacijah in seveda jasno afektivno komponento. 